\title{
8 \\ The OSCE role in Eurasian security
}

\author{
P. Terrence Hopmann
}

A wide range of institutions have appeared in the Eurasian region since the end of the Cold War that have a role to play in Eurasian security. Indeed, it has often been observed that Europe after 1989 is 'institutionally thick', that is, it is crisscrossed by an extensive web of multilateral institutions designed to prevent, deter, manage and resolve conflicts that might appear in the region once occupied by the former Communist states of the Soviet Union and its Central and East European allies. Among these institutions the OSCE is unique, mainly because it is the one institution that has a clear-cut mandate in the field of security that also includes all of the parties involved in Eurasian security, including 55 participating states extending from 'Vancouver to Vladivostok' the long way around.

The Conference on Security and Cooperation in Europe (CSCE), ${ }^{1}$ the forerunner of the OSCE, opened in Helsinki in 1973 and produced the Helsinki Final Act signed at a summit conference in the Finnish capital on 31 July-1 August 1975. During the Cold War years, the CSCE focused primarily on ten principles for security (the 'Decalogue'), a series of confidence-building measures to reduce fears of surprise attack between NATO and the Warsaw Treaty Organisation, and on human rights and expanded human contacts across the East-West divide through the centre of Europe.

Since the end of the Cold War, conflict prevention and resolution have moved to the forefront of the OSCE's agenda. Yet these roles performed routinely by the OSCE and its missions and field activities have gone largely unnoticed in governments and especially in the general public, not only in the United States but in much of Europe as well. We are all painfully aware of the failures of conflict prevention in the former Communist regions of central and eastern Europe and Eurasia. Names like Bosnia-Herzegovina, Kosovo and Chechnya - previously known only to regional specialists - have become household words and appear in our media almost daily. Yet successful conflict prevention receives virtually no attention since, by definition, 
'nothing happens' - and we all know that 'nothing' never makes the news or excites the attention of policy-makers and public officials.

Therefore, when the 'dogs don't bark' - when a potential conflict does not erupt into violence or when an old conflict remains dormant for many years - we may easily overlook the fact that this may be due to skilful and foresighted diplomatic initiatives taken outside the glare of public attention. In fact, patient but often overlooked preventive diplomacy by OSCE missions and field operations has frequently made a significant contribution to the avoidance of violence in a number of potentially dangerous situations in the OSCE region, and that other conflicts have been moderated or prevented from escalating is further due to the rapid, but often unseen, work of these OSCE officials.

Within the Eurasian region only the OSCE - in particular the Conflict Prevention Centre (CPC), with its missions and field activities, as well as the High Commissioner on National Minorities (HCNM) - has a clear mandate, organisational structure, and significant acquired experience in the field of conflict management. When combined with the 'human dimension' that infuses all of the OSCE's work, this conflict-prevention capacity constitutes the special contribution that only the OSCE brings to the European security 'architecture'. This is an especially important function that needs to be nurtured and strengthened with the active support of the OSCE's largest, wealthiest and most powerful participating states, especially the United States.

\section{The special role of the OSCE}

In the field of medicine, the principle that 'an ounce of prevention is worth a pound of cure' has long been accepted. The US government and private sources devote billions of dollars every year to research on preventive medicine, because the best way to deal with the most deadly killers such as cancer and heart disease is by preventing their occurrence in the first place. Unfortunately, this simple principle has not yet been widely accepted in the field of foreign policy. For whatever reason, it seems to be easier to achieve a political consensus behind the deployment of large and expensive military peacemaking and peacekeeping operations than to provide the much smaller resources generally needed to carry on the activity of multilateral preventive diplomacy. Thus, for example, the entire annual US assessment for all OSCE activities, including its missions, amounted to only about $\$ 20$ million in fiscal year 2002. At the same time the United States spent over $\$ 4$ billion annually to pay for the cost of US forces stationed with SFOR in Bosnia-Herzegovina and with KFOR (Kosovo Implementation Force) in Kosovo. Thus the US contribution to conflict prevention in the OSCE region was approximately equivalent to what it spent in just two days to maintain its military presence in those two regions where violence occurred. As budg- 
etary pressures become more stringent, and political opposition grows against the large-scale deployment of US troops overseas, perhaps US political leaders will learn that the need for such interventions might be averted if they invested even a small fraction of those resources into the less visible, but often more important, work of conflict prevention. But this too requires a shift in institutional focus: while it is NATO that implements peacekeeping operations, the North Atlantic alliance has little or no capacity to engage in conflict prevention. That vital role in conflict prevention, management and resolution represents the comparative advantage of the OSCE, and it is to the OSCE that the United States should give its support to perform this role more effectively.

It is interesting to speculate about how much might have been saved if the United States had only devoted more resources, attention and effort to conflict prevention before either of the conflicts in Bosnia-Herzegovina and Kosovo exploded into violence. But this is not just a matter of saving budgetary resources, however important that is. Nor is it first and foremost a question of avoiding politically difficult choices about deploying US troops in yet one more overseas operation, although that too is an important consideration. It is mostly about preventing the tragic consequences of war for the innocent people who are its inevitable victims. Before the NATO-led deployments took place in Bosnia and Kosovo, thousands of residents of these regions lost their lives; physical infrastructure, homes, farms, schools and factories were destroyed; the bare rudiments of social connections across different ethnic groups were severed; and the human spirit of the peoples surviving in all of these regions was crushed by the violence that swept across their societies.

Rebuilding from the physical damage is the easy part; re-establishing mutual trust among peoples who have lived alongside one another for centuries and who must inevitably continue to do so for the foreseeable future will be far more difficult. Yet this is essential if the foundations of a functioning civil society are to be constructed, if individual human rights and the rights of persons belonging to minorities are to be respected, and if democratic governance is to be established. For all of these reasons, one clear lesson that emerges from the recent experience in Bosnia-Herzegovina and Kosovo (and for that matter from the Russian experience in Chechnya) is that it is a lot harder to 'put Humpty Dumpty back together again' than it would have been to prevent him from falling off the wall in the first place.

Preventing the outbreak of war throughout the entire OSCE region is the principal challenge that faces the OSCE today. Furthermore, there is no other multilateral institution or individual country at present that can perform this role. Even before the end of the Cold War, Europe was crisscrossed with a wide variety of multilateral security institutions. Since 1990, most of these have expanded their functions, and the web of institutions has become even thicker: NATO has been enlarged and transformed, the EU has expanded and 
adopted a 'common foreign and security policy', and the OSCE has created institutions such as the $\mathrm{CPC}$, the Office of Democratic Institutions and Human Rights (ODIHR) and the HCNM. The UN continues to have an important role to play in European security, as does the Council of Europe. Yet within this region only the OSCE has a clear mandate, an organisational structure, and significant acquired experience in the field of conflict prevention and resolution.

NATO has long been an important institution for deterring aggression against its members by promising a collective response in defence of its member-states if they are attacked from outside. Since the early 1990s, it has developed a significant peacekeeping capability as well. By its very nature, NATO is a military organisation that can support but not supplant diplomatic institutions in preventing the outbreak of violence and promoting the resolution of existing conflicts. Almost by definition, the introduction of NATO troops into a country experiencing conflict means that the point of no return is about to be, or already has been, crossed. At this point, efforts to achieve political solutions have usually been abandoned in favour of providing some form of 'temporary' military security. The role of the OSCE missions and of the HCNM, by contrast, is ideally to enter into a situation long before it reaches the violent stage. By trying to assure full rights for all citizens in multinational states and by providing facilities for mediation and conflict resolution at the grassroots level, these institutions seek to head off incidents before they reach the boiling point.

A further limitation of NATO is that it is still viewed with considerable scepticism in many of the regions of Eurasia most threatened with conflict, a legacy of the Cold War and of the fact that some countries, especially Russia, are not members and are not likely to become so within the foreseeable future. To be effective in conflict resolution at the local level, it is necessary that outsiders not be perceived to be injecting global political issues into the already complex set of local issues. Once again the OSCE has a comparative advantage over other institutions owing to the universal participation of all states in the region where it operates.

The EU has also sought to play a major role in some conflicts in the OSCE region, and the adoption at Maastricht in 1991 of a "common foreign and security policy' was supposed to signal a more active collective diplomatic effort on the part of the EU. However, so far EU efforts have been plagued with considerable inconsistency and policy differences among its memberstates, and the outlines and priorities of the common foreign and security policy have emerged slowly, if at all. Furthermore, there has been a tendency for the EU to try to demonstrate its bona fides in the field of conflict prevention and resolution by intervening in situations where other institutions and NGOs were already at work, often causing confusion and institution shopping' on the part of disputants, and at times even undermining other efforts that might have promoted a successful resolution of disputes. The EU also 
suffers from the fact that two states - namely the United States and the Russian Federation - that play a fundamental role in European security are not among its members. In short, the EU has an essential role to play in contributing to the economic recovery and development of its neighbours to the east; the prospect of eventual membership provides a compelling reason for those states to undertake the difficult tasks required by democratisation and economic reform. But its role in conflict prevention, resolution and peacekeeping has yet to be established or validated on the basis of its record to date.

Many of the same limitations apply as well to the Council of Europe, whose membership automatically excludes the United States and Canada and is likely to restrict the participation of Russia and other post-Soviet states. Furthermore, the focus of the Council of Europe has been primarily on issues of human rights and democracy building. Although the Council sets up strict standards for admission, once admitted a country largely escapes long-term monitoring and enforcement. This contrasts with the OSCE longterm monitoring that observes over time and on-site how well participating states actually live up to the obligations they have taken on. Thus, the Council of Europe has not been engaged in long-term security building on the ground in zones of potential or actual conflict.

This leaves the OSCE as the only multilateral institution with a mandate and capacity to carry out the functions of conflict prevention and resolution in areas of tension within the broad European region it covers. Furthermore, this capacity has grown considerably throughout the past decade and, as I will argue below, its potential for further growth is great. When the CPC was first created by the Charter of Paris in 1990, it had a very limited mandate and a minute budget and staff. After the sad experience of the former Yugoslavia in 1991, the CPC's capacity gradually grew to the point where in 2002 there were OSCE missions and other field activities in eighteen countries and regions of Eurasia: six in Southeastern Europe, three in post-Soviet Eastern Europe, four in the Caucasus, and five in Central Asia. In the cases of BosniaHerzegovina, Croatia and Kosovo those missions have also grown quite large, as the OSCE has been charged with significant political roles in rebuilding these war-torn regions, operating in two of those venues alongside the NATO-led forces of SFOR and KFOR. The missions have also been supported by two OSCE organs based outside of the country, namely the ODIHR, which supports missions activities in areas such as democratisation, elections, the rule of law and human rights, and the HCNM, who works with missions in conflictprevention and conflict-resolution activities in disputes involving ethnonational groups or between central governments and persons belonging to minority groups. The chairperson-in-office and other member governments serving in the OSCE troika (the chair, past-chair and chair-elect), as well as officials of the OSCE Secretariat and CPC in Vienna, frequently provide assistance at the highest levels to the field missions and activities. 


\section{The OSCE institutional capacity for conflict management in the Eurasian region}

In the aftermath of the collapse of the Berlin Wall, the OSCE began to increase its capacity to manage conflicts despite the very modest mandate of the CPC. After the outbreak of violence that occurred in both the former Soviet Union and the former Yugoslavia in the first two years of the decade, the OSCE substantially strengthened its institutional capacity in this area at the Helsinki Summit of 1992. The mandate for the CPC was reinforced, and the first mission of long-duration to be stationed in a region of conflict was created for the regions of Kosovo, Vojvodina and Sandjak within the Federal Republic of Yugoslavia. Of equal importance, the office of the HCNM was created. Together, these two institutions have functioned as the core of the OSCE's conflict management work throughout the Eurasian region.

The CPC is located within the secretariat in Vienna and is primarily responsible for coordinating the work of the OSCE missions and other field activities. It is largely responsible for staffing and training missions, for coordinating their work in the field, and for liaison between the missions and other OSCE institutions and participating governments. It is thus the CPC that provides the primary point of contact between each of the field missions and activities and OSCE officials in Vienna. Prior to the 2000 reorganisation, all arrangements to staff and supply the missions with necessary materials were provided by the CPC. Presently, the CPC still serves as the communications link through which instructions are normally relayed to mission heads, and mission heads normally convey all reports, both routine and special, through the CPC office in Vienna. Although the staff of the CPC in Vienna was recently enlarged, it is still quite small in proportion to the number of missions that must be supported, a reflection of the limited budgetary resources available to it. The staff in 2001 consisted of three professional officers, including a director and deputy director, supported by 14 contracted staff members. Therefore, it is often necessary for the staff to prioritise their responses to the requests of each of the field missions.

At the time of its founding, the CPC focused mostly on the implementation of various military confidence- and security-building measures (CSBMs), especially those included in the agreement known as Vienna Document 1990. These included the following:

- providing an information and database regarding military forces and activities in the OSCE region, including force size and deployment, military budgets, and a calendar of annual manoeuvres and other military movements that were required to be reported under the terms of Vienna Document 1990;

- providing a locus and infrastructure for consultation and coordination regarding any unusual military activities not reported through the 
Vienna mechanism that might give rise to concern of impending military activity of a threatening nature;

- coordinating the responses of countries with regard to hazards resulting from military activities or incidents involving military forces before they could set off a chain reaction of potentially violent responses;

- organising annual meetings to assess the performance of participating states with regard to the implementation of all CSBMs agreed to under CSCE provisions.

The Charter of Paris thus anticipated the possibility that the CPC's initial functions might be expanded as the need arose. Following the outbreak of fighting in the former Yugoslavia, the CSCE ministerial meeting in Prague in January 1992 created the framework for expanding the functions of the CPC, opening the door to the creation of its present structure. Based on the concept of responding to unusual military activities, the possibility of long-term monitoring to provide 'early warning' of impending threats to the security of states and persons in the region became a central function of the CPC during and immediately after the 1992 Helsinki follow-up meeting. Therefore, the concept of the 'mission of long duration' emerged, and the CPC was given the task of organising and overseeing the operation of these missions.

In the event that missions provide 'early warning' to the CPC of incipient conflict, it is the CPC's primary responsibility to see that OSCE institutions and participating states are alerted to the potential danger, as well as to prepare to implement any decisions taken by the Permanent Council or other high-level institutions. This often requires the director to deliver 'early warning' messages to the appropriate OSCE institutions and to prepare to implement decisions taken by those institutions. The director also frequently travels to the site of potential conflicts to meet with local officials or with parties involved in local conflicts to provide assistance and backing for the work of the mission.

A further reorganisation of the CPC took place in 2000 as a result of the Istanbul Summit conference and the decision to create the Rapid Expert Assistance and Cooperation Teams (REACT) system for recruiting and training mission staff. As a consequence an Operations Centre was created within the CPC to provide for advanced planning of all aspects of future OSCE missions, including the deployment of civilian police. The Operations Centre also created the position of liaison officer to become a point of contact between the OSCE and other international organisations, both military and civilian, that might be involved alongside the OSCE in regions experiencing conflict. The new Operations Centre includes a 'situation room' which can maintain contact at all times ( 24 hours a day, seven days a week) with all field operations and can relay information from the field to secretariat officials and to the chairman-in-office on very short notice. The mandate for the Operations Centre includes three major tasks: 
- helping to identify crisis areas by maintaining close liaison with other international organisations and NGOs involved in conflict-management activities, including but not limited to the role played by OSCE missions and field activities, but also extended to regions where no OSCE mission is currently on the ground so that information must be obtained from other international actors operating in these regions;

- serving as the planning unit for all future OSCE missions and field operations;

- acting as a point of coordination during the initial mobilisation and subsequent deployment of any future field operations mandated by the OSCE Permanent Council. This new function first operated to set up a reinstated OSCE mission to the Federal Republic of Yugoslavia in early 2001.

The CPC, directed in 2002 by Ambassador Marton Krasznai, coordinates implementation and verification of OSCE agreements on CSBMs (i.e., the 1986 Stockholm agreement, the Vienna Document 1990 and the Vienna Document 1992), although separate consultative groups promote the implementation of the Conventional Forces in Europe and Open Skies Treaties. The CPC also coordinates the work of the Forum for Security Cooperation, which meets regularly in Vienna to discuss long-term policy issues and to negotiate on arms control and CSBMs.

The HCNM in The Hague is a senior official, initially the former Dutch foreign minister Max van der Stoel, who has considerable independent authority to investigate and assist in responding to potential or actual incidents of violence where national minorities play a significant role. Many specialists on international organisations view the creation of this position at the Helsinki Summit in 1992 as one of the most creative decisions taken by the OSCE in its 25-year history, as the office has provided a function not found in most other global or regional international institutions.

Supported by a small staff, the HCNM provides early warning of brewing conflicts and intervenes in such situations where he deems it appropriate in order to assist the parties to find non-violent solutions to their disputes. Under the mandate given to the HCNM by the Helsinki Summit, he is only supposed to deal with issues involving persons belonging to national minorities, he is not permitted to deal with groups practising terrorism, and he is only supposed to deal with conflicts that have the potential to affect interstate relations or regional security. Although the HCNM reports regularly to the Permanent Council, he does not receive instructions from it (unlike the $\mathrm{CPC}$ and the missions and field activities which it coordinates), and he is free to respond according to his own judgement whenever he believes it to be appropriate. Under van der Stoel's leadership, this became a very active office in the OSCE that has operated with considerable political independence. Van der Stoel retired in 2001 and was replaced by Rolf Ekeus of 
Sweden, who is likely to continue van der Stoel's broad interpretation of the mandate for his office and be actively engaged in monitoring relations between governments and persons belonging to minorities throughout the Eurasian region.

Typically the HCNM responds to any incidents that fall within his mandate by travelling to the scene of the event and meeting immediately with the parties involved, including government officials and aggrieved parties. On the basis of his observations he may offer immediate advice to the parties, engage in third party mediation, prepare recommendations for the parties, or organise seminars or round tables at which parties may discuss their grievances. As a representative of the OSCE - an international organisation composed of national governments - the HCNM must always be aware of his obligations to the governments to whom he is responsible. Thus his role is not necessarily to act as an advocate on behalf of minorities; rather it is to promote dialogue between persons belonging to minority groups and governments or other institutions and organisations representing the national majority. His goal is to promote the successful integration and acceptance of persons belonging to minority groups within the structures of a multinational state and, in so far as it is possible, to seek to head off pressures for secession by regions heavily populated by persons belonging to minority groups. ${ }^{2}$

Frequently the HCNM has travelled to countries and regions where there is not an established OSCE mission or field activity. In this way, he has been able to intervene in situations where short-term assistance is needed, but where a longer-term presence is not necessary. However, whenever the HCNM has concluded that a more continuous presence by OSCE representatives is desirable in a region, he has recommended to the Permanent Council that a mission or field activity be set up. Indeed, a substantial number of the missions now fielded by the OSCE have come into existence in part as a consequence of recommendations by the Commissioner. Once a mission is on location, however, that does not necessarily mean that the role of the HCNM disappears from the region. Although most OSCE missions and field activities have at least one human rights specialist on their staff, their work can often be supplemented by the involvement of the Commissioner, especially when the issue concerns the rights of persons belonging to minorities as opposed to violations of individual human rights.

Therefore, the HCNM has often appeared in countries where OSCE missions are established and functioning. In these cases, the on-site mission has been in part responsible for arranging the logistics of the visit by the Commissioner, for briefing him about the situation on the ground, and for assisting him with the follow-up to his visit. On rare occasions there have been tensions between mission members, who often feel that their continuous presence gives them a more in-depth knowledge of the situation in a particular country, and the Commissioner, who enters into many regions of 
conflict where he necessarily must operate on the basis of a concern for general principles of minority rights rather than according to the details of the local situation. On the other hand, in most cases the OSCE missions and the office of the HCNM have collaborated closely in their effort to resolve underlying tensions involving the rights of persons belonging to minorities. Ideally, their relationship should be complementary rather than competitive. The local mission members typically do have more intimate knowledge of the local situation, whereas the prestige and international standing of the HCNM generally give him the clout necessary to persuade governments and leaders of minority groups to pay serious attention to his recommendations, which is not always the case with regard to recommendations made by OSCE mission staffs. Therefore, the HCNM and the mission human rights specialists each have their own special role to play, and through close collaboration they can best advance the OSCE's role in resolving tensions surrounding national minority issues in many of the OSCE participating states.

One of the most innovative roles performed by van der Stoel during eight and a half years in office was to create what has come to be known as 'seminar diplomacy'. Typically, this approach involves inviting leaders of national minorities and leaders of majority groups as well as government officials to small seminars, often in isolated locations where they can deliberate outside of public attention. In general, the HCNM also invites to these seminars a small set of international 'experts' from OSCE countries on issues such as human rights, minority rights, constitutional law, shared power and autonomy, and federalism/confederalism. Through intense interactions over several days, the Commissioner seeks to acquaint all parties with international norms and practices for dealing with minority groups and their integration into multinational states. These seminars also provide an opportunity for the parties to express their own grievances in the presence of an audience of international experts, who may then make recommendations to the parties about how to overcome their differences. In most cases, the HCNM follows up these seminars with a set of written recommendations to the parties based on what he learned from the seminar, as well as a series of follow-up visits to promote direct negotiations between the parties in an effort to resolve their differences. Through a continuing series of back-and-forth exchanges of information and ideas, therefore, the High Commissioner may hope both to educate the parties about international standards and norms and to bring them together around solutions based on those broadly acknowledged principles. The HCNM has thus been one of the OSCE's most effective instruments for promoting conflict resolution throughout central and eastern Europe and the former Soviet Union (FSU).

\section{Specific OSCE conflict prevention and resolution activities since $1991^{3}$}

OSCE field activities may be categorised into five different functions that they perform in countries experiencing potential or actual violent conflict. Most 
missions and field activities perform multiple functions, but for purposes of this chapter I focus on prominent examples that illustrate each of these different functions. I will thus highlight each of these five functions and present a brief evaluation of the major accomplishments and shortcomings of the OSCE in performing each of them: ${ }^{4}$

- Virtually all OSCE missions promote long-term conflict prevention through encouraging the development of democratic institutions and procedures and respect for human rights and the rights of persons belonging to minorities, and for many missions this serves as the principal task assigned by their mandates.

- Many OSCE missions seek to prevent the escalation of conflicts to the level of violence through various forms of diplomatic intervention, including efforts at conciliation and mediation of disputes.

- Occasionally, but rarely, OSCE missions may actively mediate ongoing violent conflicts, seeking a ceasefire as a precursor to introducing nonviolent methods for the eventual resolution of the conflict.

- Once violence has ceased, OSCE missions often seek to promote through negotiations a long-term resolution to the underlying issues of the conflict.

- Many OSCE missions have focused on rebuilding societies and re-establishing security in the aftermath of violent conflict.

\section{Long-term conflict prevention through democratisation}

It has become a generally established finding of social science research that democracies generally do not go to war with other democracies; furthermore, intra-state or civil conflicts are less likely to occur in societies that have well-established procedures for the non-violent resolution of conflicts of interest among their citizens. ${ }^{5}$ Therefore, the establishment of democratic processes, the creation of governments of laws and not of individuals, and processes to integrate persons belonging to minorities fully into the institutions of the state are together the best long-run guarantors of peace. Examples include Estonia and Latvia, where the OSCE played a significant role on behalf of large minorities of ethnic Russian denied citizenship rights in these Baltic states; indeed, these missions achieved sufficient results so that they were closed down at the end of 2001. Furthermore, the OSCE has embarked since 1998 upon an effort to defend democracy in Belarus against an authoritarian government that has reversed that country's early postSoviet progress in the field of democratisation. As one of a very few international institutions operating in Belarus, the OSCE Advisory and Monitoring Group has played a vital role in providing international protection for NGOs and a severely restricted political opposition within that country.

Difficulties in the process of democratisation have also arisen in the five Central Asian states that emerged from the collapse of the Soviet Union with 
strong leaders in charge, and the democratisation process has been slow to take hold. Therefore, in 1995 an OSCE Liaison Office in Central Asia was established in Tashkent, the capital of Uzbekistan. This effort was enlarged in 1998 with the establishment of OSCE centres in the capitals of three other Central Asian republics: Kazakhstan, Kyrgyzstan and Turkmenistan. (The fifth Central Asian state, Tajikistan, has a full-scale OSCE mission operating on its territory with a more specific mandate in the field of conflict management that will be discussed below.) The focus of OSCE efforts in Central Asia has been on stimulating education about democratisation and human dimension issues. In each case, numerous seminars have been organised with local political elites and NGOs in which outside specialists on topics such as criminality and drug trafficking, legislative changes that would promote greater foreign investment, regional environmental problems, sustainable development, and CSBMs among ethnic communities and with neighbouring states. In addition, the OSCE has worked closely with local universities and other educational institutions to try to institutionalise these topics in their curriculum.

In all of these efforts, it is important to realise that democratisation is an extremely difficult and long-term task even in the best of circumstances. Centuries of authoritarian rule throughout the region have created a climate in which few persons if any were alive in 1990 who had ever lived in a democratic state. As a result, the transition to a fully democratic society, in which more than the outward appearance of democracy is established and in which democratic values are truly internalised throughout the population, is unlikely to take place rapidly. Democracy is inherently fragile in all transitional societies, and more immediate measures of conflict prevention and resolution will frequently be required in order to avoid an outbreak of violence that might set back the democratisation process by a decade or more. The linkage of security to political and humanitarian concerns epitomises the special role that the OSCE missions have come to play in societies undergoing political transformation since the collapse of communism.

\section{Prevention of violent outcomes in potential conflict situations}

As noted above, a major function of the OSCE has been to prevent 'Humpty Dumpty' from falling off of his wall. The organisation's record in this case is mixed. However, the OSCE has often been blamed unfairly for failing to prevent conflicts. Too often OSCE inaction was the result of the refusal by one or more of its participating states to take action recommended by OSCE mission heads or other officials such as the HCNM; that is, by the failure to obtain the consensus that is required to take decisive action. Furthermore, in the early post-Cold War years the OSCE did not have a sufficient structural capacity to respond to brewing conflicts.

Thus the conflicts in Croatia and Bosnia-Herzegovina were well under way by the time the first CSCE mission of long duration was sent into the field 
in late 1992, following the Helsinki follow-on meeting that summer. In the case of Kosovo, the OSCE was hamstrung by the fact that it had suspended the Federal Republic of Yugoslavia from participation in May 1992. Although there were many good reasons for this action, it also had the perverse effect of preventing the OSCE from having any access on the ground in the Kosovo region until tensions had passed the point of no return. By the time the United States, led by Ambassador Richard Holbrooke, persuaded the parties to accept an OSCE Kosovo Verification Mission on the ground in October 1998, it was too late to realise a peaceful resolution of the conflict. A similar decision a year or more earlier, however, might have prevented the bloody war and subsequent international occupation of Kosovo, although of course it is always impossible to prove "what might have happened if .... But it is very clear that the OSCE and especially the special representative of the chairman-in-office, Ambassador Max van der Stoel, provided substantial 'early warning' of impending disaster in Kosovo. It was the failure of key participating states - including the United States - to take 'early action' in the form of active diplomacy prior to late 1998 that permitted the outcome in Kosovo to be so violent and the subsequent task of reconstruction so enormous.

Looking at the other side of the coin, the OSCE has contributed to the successful resolution of potentially violent conflicts in several regions of Eurasia. Perhaps most notable is the role played by the OSCE in mediating between nationalistic ethnic Russian politicians in Crimea and the central government of Ukraine, which was critical in reaching a solution to that volatile conflict that could have easily exploded into violence. Russian nationalists wanted to separate Crimea from Ukraine and perhaps return it to its pre-1954 status as a part of the Russian Federation, and the Ukrainian government was prepared to do anything necessary to prevent this from happening. Special credit here goes to the OSCE's HCNM, van der Stoel, whose continuing intercession, often using the problem-solving workshops referred to above as 'seminar diplomacy', played a major role in promoting a non-violent outcome in this potentially grave situation. Van der Stoel's work was also backed up by continuous efforts of the OSCE mission members in both Kyiv and Simferopol to broker a solution guaranteeing substantial Crimean autonomy while preserving the territorial integrity of Ukraine. Furthermore, this effort was especially important due to the strategic significance of the region. Needless to say, a war in the mid-1990s between Russia and Ukraine would have created a severe international crisis that would have affected the vital interests of the entire West, including the United States. Even if this were the only accomplishment of the OSCE in the decade of the 1990s, I would argue that this alone was worth all of the effort and resources that have been put into the entire organisation by the United States and its European allies.

But this is, of course, not the only significant accomplishment of the OSCE 
during the 1990s. At least until 2001, the OSCE mission to Skopje (the former Yugoslav Republic of Macedonia) played an instrumental role in preventing that former Yugoslav republic from falling into the kind of violence that has swept across Croatia, Bosnia-Herzegovina and Kosovo. Of course, the results of those efforts were placed in doubt as violence expanded in regions of Macedonia inhabited by large ethnic Albanian populations throughout 2001. Several factors largely beyond the control of the OSCE conspired to push the situation in Macedonia towards the brink of violence, including the collapse of the government of Albania in 1997 and the looting from its storehouses of large supplies of light weapons and munitions, which made their way into Kosovo and subsequently into Macedonia; the removal of the United Nations Preventive Deployment Force (UNPREDEP) from the northern border regions due to Chinese opposition in the UN; and the growing ambitions of some ethnic Albanian politicians to follow up their 'success' in Kosovo with a similar effort to split heavily Albanian-populated regions of Macedonia off from the rest of the country, perhaps eventually creating a 'greater Albania'.

Fear that violence was imminent, however, in turn led to a rise in nationalism among the Macedonia majority and greater restrictions on minorities, especially Albanians. At the same time, some parts of the Albanian minority, in the aftermath of the defeat of Serbian forces in neighbouring Kosovo, began to advocate separation from Macedonia and joining with Kosovo and Albania. Their separatist ambitions were fuelled by a ready availability of weapons that crossed the border from neighbouring Kosovo. As a result violence flared up in the spring of 2001 between Albanians near the border areas and the Macedonian armed forces. After a ceasefire was negotiated in the Ohrid Framework Agreement of 13 August 2001, several units of NATO troops entered Macedonia to disarm the parties, following which the armed forces were withdrawn. At the same time, the OSCE enlarged its mission in Macedonia to a total of about 210 unarmed monitors, protected by some 1,000 soldiers from France, Germany and Italy. While the OSCE's mandate remained basically unchanged, the necessity for intensive conflict prevention at the local level had been clearly indicated by the outbreak of violence and the increased radicalisation of the two communities that lay behind the violence. In the autumn, deteriorating conditions in Macedonia seriously challenged what was previously regarded as one of the more successful preventive diplomacy missions. None the less, the OSCE Spillover Monitoring Mission in Macedonia, with some timely help from NATO and the continued engagement of the OSCE HCNM, managed by the end of 2001 to head off the escalation of violence and to prevent Macedonia from proceeding down the violent path that Bosnia-Herzegovina and Kosovo had taken in the recent past. 


\section{Ceasefire mediation}

Once violence breaks out in a country, the OSCE role has generally been limited. One exception, however, was the first war in Chechnya, which started with the Russian military assault in December 1994. Shortly afterwards the OSCE Permanent Council created the OSCE Assistance Group to Chechnya, which set up operation in Grozny in 1995. Russia, as a country that still clings to its self-image as a great power, was of course reluctant to permit any presence by a multilateral organisation on its soil. Therefore, it was somewhat surprising when the Russian government permitted a small OSCE 'assistance group' to be established in the very vortex of the fighting. Under the able leadership of the second head of mission, Ambassador Tim Guldimann of Switzerland, the OSCE expanded its activity beyond monitoring human rights violations and war crimes and assumed a role as an active mediator between the Chechen leaders and officials in Moscow. Guldimann's shuttle diplomacy, involving numerous trips between Grozny and Moscow, was largely responsible for setting up the meeting at Khasavyurt between Alexander Lebed and Zelimkhan Yanderbiev that brought an end to fighting and a withdrawal of Russian troops from Chechnya in August 1996.

Subsequently, the OSCE assumed the major role in preparing, conducting and monitoring the presidential elections in Chechnya in January 1997, in which Aslan Maskhadov was elected. Sadly, the internal situation in Chechnya degenerated into anarchy, with frequent violence directed at outsiders, even those representing international humanitarian organisations. This was followed by a renewal of Russian military action against Chechnya in 1999, after the OSCE Assistance Group had moved its offices to Moscow because of fear about the safety of mission members if they remained in Chechnya. Tragically, this also resulted in a decline of OSCE influence over the parties, and extensive efforts to re-establish a mediating role for the OSCE, undertaken at the Istanbul Summit in November 1999 by the United States and several other countries, failed to bring results; indeed, only in June 2000 did the OSCE Assistance Group finally return to Chechnya. This tragic outcome, however, should not cause us to overlook completely the potential for the OSCE to play an important mediating role, even in the midst of violent conflict, as it did in Chechnya in 1995-96.

\section{Conflict resolution after a ceasefire is in place}

Since the major OSCE conflict prevention functions were created after the spate of post-Cold War violence in the early 1990s, a major focus for OSCE missions has been the effort to broker longer-term resolution of the conflicts that had produced the previous chain of violence. In addition, the OSCE has sought to prevent the renewal of violence in situations where serious tensions remain. This has been the major focus of the OSCE missions in Moldova (regarding Transdniestria), Georgia (especially regarding South Ossetia and to a lesser degree Abkhazia, where the UN has taken the lead 
role), Tajikistan, and the so-called Minsk Group dealing with the conflict in Nagorno-Karabakh.

In this area, the OSCE record is clearly mixed, and there is probably no single aspect of the work of the OSCE where performance has fallen so short of aspirations. On the positive side of the ledger, in none of these regions has large-scale violence reappeared since the OSCE missions entered. In most cases, the OSCE has played a useful role in monitoring the performance of peacekeeping forces, mostly from Russia, operating under a CIS umbrella. In addition, OSCE activities in democratisation, human rights, the rule of law, refugee resettlement, and support for the rights of persons belonging to minorities has assisted local authorities in keeping tensions below boiling point. Perhaps of greatest importance, in each case the OSCE has played a third party role in keeping lines of communications open and negotiations under way between former belligerent factions to try to resolve some of the important issues underlying these conflicts. Most of these conflicts have become frozen in place: there is no settlement, but also no return to mass violence. These outcomes are no small accomplishment, but they also leave open the potential for the OSCE to improve its effectiveness at managing negotiations to enhance its ability to bring about long-term settlement of frozen conflicts, so that life in these divided states may return to some semblance of normality.

\section{Post-conflict reconstruction and security building}

After episodes of significant violence, social relations within society are usually badly broken. Hatred, anger and the desire for revenge become dominant emotions that often reinforce the differences that produced conflict in the first place. Rebuilding war-torn societies is often a long and difficult task. It would not be appropriate to expect Serbs, Croats and Bosnians to forget about their long and bitter struggle in a few short years. Thus one of the major challenges facing the OSCE has been to try to assist societies torn by conflict in their efforts to rebuild. NATO and other multinational forces can help by providing security, both for international personnel and to prevent opposing sides from resuming violence. The EU and other international financial institutions can assist by contributing desperately needed economic aid to rebuild infrastructure and jump start economies so that they can begin to grow on their own, and thus reduce the poverty that so often becomes a breeding ground for violence. But in virtually all cases of violence in the Eurasian region, the primary responsibility for reconstructing political institutions and developing a democratic political framework for resolving differences peacefully - the most difficult task these regions face - has fallen overwhelmingly to the OSCE.

This activity has been the major focus of some of the largest of the OSCE missions, including those in Croatia, Bosnia-Herzegovina and Kosovo. It has also been the primary task of the OSCE presence in Albania, as well as an 
important function of the missions in Georgia and Moldova. In many ways, the OSCE's activities in this category are those of long-term democracy building, where the OSCE faces the especially difficult challenge of operating in a post-conflict situation. The OSCE's close cooperation with other security institutions, especially the UN, NATO and the EU, is particularly necessary in these regions. In the effort to revive these war-torn societies, the OSCE cannot succeed alone, but its contribution is none the less essential to the successful accomplishment of this task.

\section{Evaluation and recommendations}

In summary, when one surveys all of the myriad activities that the OSCE has undertaken since the early 1990s in the field of conflict prevention and resolution, one cannot escape the conclusion that, in spite of all its shortcomings and failures, it plays a much more significant role than it is generally credited with. The OSCE deserves a place of at least equal status with NATO when evaluating the role that multilateral institutions play in contributing to security in the North Atlantic and pan-Eurasian region. The OSCE's role often goes unrecognised, in part because it works in so many relatively obscure locations, and because most of its successes are the consequence of thousands of small accomplishments achieved day by day, village by village, rather than any single, dramatic result that can readily be pointed to.

Furthermore, as noted previously, when it is most successful, very few people notice and thus very little credit is given where credit is due. The failures - Bosnia-Herzegovina, Chechnya and Kosovo - make headlines. The successes can be uncovered by outsiders only with painstaking and difficult research about potential crises that never materialised. The many accomplishments on a daily basis, often small achievements individually, but of great importance collectively, are easily overlooked. The men and women who serve in OSCE missions, in the staff in Vienna, The Hague and Warsaw, and in national delegations to the OSCE institutions, are often making significant accomplishments in heading off crises for which they seldom, if ever, receive the credit they deserve. The OSCE is certainly not a panacea and cannot bring peace to Eurasia alone, but without its steadfast work throughout the region, it is extremely likely that violence, violation of human rights and degradation of the human spirit would be far more widespread than they are today.

That having been said, the next question naturally arises: can the OSCE do better at its conflict-prevention and conflict-resolution functions? And if so, what needs to be done to strengthen it? The answer to the first question is definitely 'yes'. The question of how to strengthen the OSCE is somewhat more complex. ${ }^{6}$ One of the strengths of the OSCE is that it is a relatively small, non-bureaucratic and flexible body, in notable contrast to many other multilateral organisations. Any effort to strengthen the organisation must 
be careful not to undermine its flexibility and resilience, which are essential to its ability to respond in a timely fashion to brewing conflicts.

None the less, there are several modest steps that might strengthen the OSCE's capacity to work effectively in conflict prevention and resolution without entailing great costs or the creation of a large, cumbersome bureaucracy. First, the OSCE needs a more professionally competent, well-trained staff, especially in its missions. At present, it depends too much on short-term volunteers and personnel seconded to the OSCE by the participating states. Many of these people go into the field with little or no knowledge about the region where they are being sent, and little or no training about the process, skills and techniques of conflict resolution. Many are selected to serve on missions because they are available for short-term assignments, or they are seconded by governments that do not need their services elsewhere. Most are on short-term contracts that too often expire just as the people are beginning to get a grasp of the issues with which they are supposed to be dealing. In spite of these limitations, many OSCE personnel have done an excellent job. Yet they could do much better with proper training and enough time in the field really to learn their job and how to perform it effectively.

The REACT program was initiated at the Istanbul Summit in 1999 to recruit and train staff for OSCE missions, especially for emergency missions that must be established with a short lead-time. Each participating state is expected to maintain a roster of qualified and trained individuals who can be called up at short notice to be deployed in areas of developing conflict. REACT has produced some enhancements in training OSCE personnel, but this programme still depends on each participating state to train its own volunteers, and the results are inconsistent at best. Heads of missions are generally very qualified senior diplomats, but they too often have to work with very limited resources and inexperienced, inadequately trained personnel. And the challenge of finding the right people quickly, when they are most needed to head off developing emergencies, remains a serious one that the OSCE must figure out how to surmount.

Similarly, the OSCE could benefit from a strengthened analytical office and information resources in the CPC in Vienna. A small group of highly trained specialists in each of the major mission functions - elections, human rights, rights of persons belonging to minorities, democratisation, freedom of the media, conflict prevention, mediation and conflict resolution - could provide enhanced support to each of the missions when needed. A better library and access to Internet resources could provide enhanced information for missions in the field, which often work in isolated locations. Although the recently created Operations Centre in Vienna has substantially improved the OSCE's capacity to receive and process 'early warning' messages about incipient conflicts and get that information rapidly into the hands of those capable of developing an early response, it depends heavily on the quality of information received from the field and has only a limited capacity to analyse 
and evaluate that information when it reaches Vienna. Therefore, the OSCE is still often challenged by the difficult task of authorising action prior to the point of no return; when the cycle of violence has escalated out of control, OSCE preventive action is no longer sufficient to head off an escalatory spiral.

Second, the OSCE also needs to develop a greater capacity to engage proactively in order to mediate serious conflicts that appear to be on the brink of violence or that have become frozen in the aftermath of violence. The HCNM represents a model of an OSCE official who can enter into disputes rapidly and without any special mandate, enabling him or her to respond on the spur of the moment. Many other OSCE institutions, however, remain mired in potential paralysis created by the need to find consensus (or approximate consensus) within the Permanent Council, where all 55 participating states are represented. Moving from the recognition that a problem is brewing to a political decision to initiate a timely response remains the Achilles heel of almost all international organisations.

In order to begin to overcome these obstacles to timely response, the OSCE should create a greater institutional capacity to bring 'eminent persons' to intervene on their own initiative in extremely sensitive or urgent situations. This can be done in part by upgrading the status of the OSCE's secretary general, who now plays primarily an administrative role; as a consequence, the secretary general is not generally available to play the kind of role played by the UN secretary general in many severe crises where his or her personal intervention may produce positive results when all other efforts have failed. Political leadership for the OSCE is provided by the chairperson-in-office, but this position rotates every year, so that there is not sufficient continuity or consistency from one individual to the next to enable this person to play a long-term role as ombudsman or mediator. Sometimes, of course, the OSCE can rely on eminent persons coming from among its participating states, as was the case when Richard Holbrooke assumed an important mediating role on behalf of the United States in the conflicts in both Bosnia-Herzegovina and Kosovo. However, it is far better in principle for such individuals to operate within the OSCE framework, except in extraordinary circumstances, since the representative of a multilateral institution will generally be accorded greater legitimacy by disputing parties than will the representative of any single participating state.

In addition, the OSCE often lacks the instruments to influence states to change behaviours that undermine the commitments undertaken under the Helsinki Final Act and the other subsequent documents that have been adopted by the OSCE. In many cases, the more influential states will have to support the OSCE by exerting pressure on intransigent states that resist OSCE efforts to promote democratisation and other improvements in the 'human dimension'. For example, the United States and the Russian Federation need to cooperate to encourage highly authoritarian states such as those in Central Asia and the Caucasus, as well as Belarus, to live up to their commit- 
ments undertaken within the OSCE framework. They also should work together more effectively to reinforce OSCE efforts to broker solutions to the most important 'frozen conflicts', such as those in Moldova, Georgia and Nagorno-Karabakh.

Therefore, the US government needs to encourage the Russians to take their own rhetoric about the potential for the OSCE seriously. In the early post-Cold War years, Russian rhetoric emphasised the primacy of the OSCE among European security institutions. The Russians seem to have largely abandoned that effort following their failure to block the enlargement of NATO. But that does not mean that the United States should give up encouraging them to make more effective use of the OSCE to deal with the many and serious security threats that surround them on all sides. Furthermore, the United States can best convince the Russians to take the OSCE seriously by taking it seriously itself. The United States should give the OSCE the same priority it gives to NATO in dealing with broad European security issues, while recognising the different strengths of both institutions. Unless the United States can help enhance the OSCE's capacity to prevent new violent conflicts and to resolve conflicts that recently produced violence, we are likely to be faced with a continuing series of hard choices: either the United States will have to send more troops abroad in politically unpopular missions, an especially difficult task since the US military priority shifted to combating terrorism; or the United States will be forced to stand by while violence and instability spread across regions of Europe and Eurasia, creating, among other negative consequences, fertile ground for terrorist groups to form and flourish.

Similarly, European institutions like the EU or the Council of Europe cannot be counted on to deal with all crises that arise on their own continent. The Europeans also need to give the OSCE significant priority alongside their efforts to enlarge and strengthen the EU. They need to be realistic about the ability of an expanding EU to reach a consensus about foreign and security policy. Even if they are successful in that endeavour, their capacity to implement effective action is likely to be limited without the close cooperation of the United States and/or Russia. And such cooperation can best be achieved when they work within the framework of the one European security institution in which those two countries are represented, that is, the OSCE.

In the process, US officials and the attentive public might come to realise that the OSCE also serves long-term US interests by helping to create a more stable, peaceful and democratic regime in those regions of Eurasia formerly ruled by Communist governments. Indeed, this is a vital interest that all OSCE participating states share, even though they do not always fully recognise this convergence of interest. Promoting collective action to support these goals of cooperative security throughout the OSCE region thus ought to be a high-priority goal for US foreign policy. 
Finally, the United States should encourage other regions of the world experiencing insecurity and violence to consider borrowing, when appropriate, concepts and approaches to regional security that have been successful in the Eurasian context. Of course, security in each region is influenced by different cultural, political and strategic environments. But the OSCE has shown that intervention by a regional security institution may be undertaken with greater sensitivity to the local conditions, greater awareness of the underlying issues, and deeper understanding of specific regional concerns than is generally possible for global international organisations like the UN or global hegemonic powers like the United States. In several instances the Organisation of African Unity and the Asian Regional Forum have begun to experiment cautiously with some of the confidence-building measures and techniques of preventive diplomacy developed by the OSCE. Thus, with due sensitivity to regional variations, the OSCE also offers a model of how a regional security organisation can strengthen security and promote democratic development in volatile regions of the world, and its value as a model ought to be taken seriously in all regions of the globe threatened with instability and violent conflict.

\section{Notes}

1 The CSCE was renamed the OSCE in 1995 to reflect the fact that it had evolved from a series of itinerant conferences to a fully institutionalised organisation.

2 Ambassador van der Stoel has summarised his philosophy for responding to conflicts involving the rights of persons belonging to minorities as follows: '.. . the protection of persons belonging to minorities has to be seen as essentially in the interest of the state and of the majority. Stability and security are as a rule best served by ensuring that persons belonging to national minorities can effectively enjoy their rights. If the state shows loyalty to persons belonging to minorities, it can expect loyalty in return from those persons who will have a stake in the stability and well-being of that state ... solutions should be sought as much as possible within the framework of the state itself'. Quoted in Connie Peck, Sustainable Peace: The Role of the UN and Regional Organizations in Preventing Conflict (Lanham, MD: Rowman and Littlefield, 1998), p. 45.

3 Throughout the decade from 1992 through to 2001, I was engaged in research to evaluate the effectiveness of OSCE missions and field activities. I was assisted in this endeavour by support from the Center for Foreign Policy Development at Brown University in 1992, a Fulbright Fellowship to the OSCE based in Vienna in 1997, and a Jennings Randolph Senior Fellowship at the US Institute for Peace in Washington in 1998. As part of this research, I conducted extensive interviews with heads of mission; attended numerous OSCE meetings, including regular meetings of the Permanent Council; read the activity reports of missions from throughout this period; and made on-site visits to several OSCE missions in the field. The evaluations and conclusions presented below draw primarily from my own observations and analysis in conducting this research rather than from secondary sources. 
4 For a further exploration of these roles and some primary examples of their successful performance by the OSCE, see my chapter in a book released by the Committee on International Conflict Resolution of the US National Academy of Sciences: P. Terrence Hopmann, 'The Organization for Security and Cooperation in Europe: Its Contribution to Conflict Prevention and Resolution', in Paul C. Stern and Daniel Druckman (eds), International Conflict Resolution After the Cold War (Washington, DC: National Academy Press, 2000), pp. 569-615.

5 See Bruce M. Russett and John Oneal, Triangulating Peace: Democracy, Interdependence and International Organizations (New York: Norton, 2001), Ch. 1. For a more sceptical assessment of the democratic peace hypothesis, see Joanne Gowa, Ballots and Bullets: The Elusive Democratic Peace (Princeton, NJ: Princeton University Press, 1999).

6 A more detailed set of suggestions about how to strengthen the OSCE may be found in P. Terrence Hopmann, Building Security in Post-Cold War Eurasia: The OSCE and U.S. Foreign Policy (Washington, DC: United States Institute of Peace, Peaceworks No. 39, 1999). 